
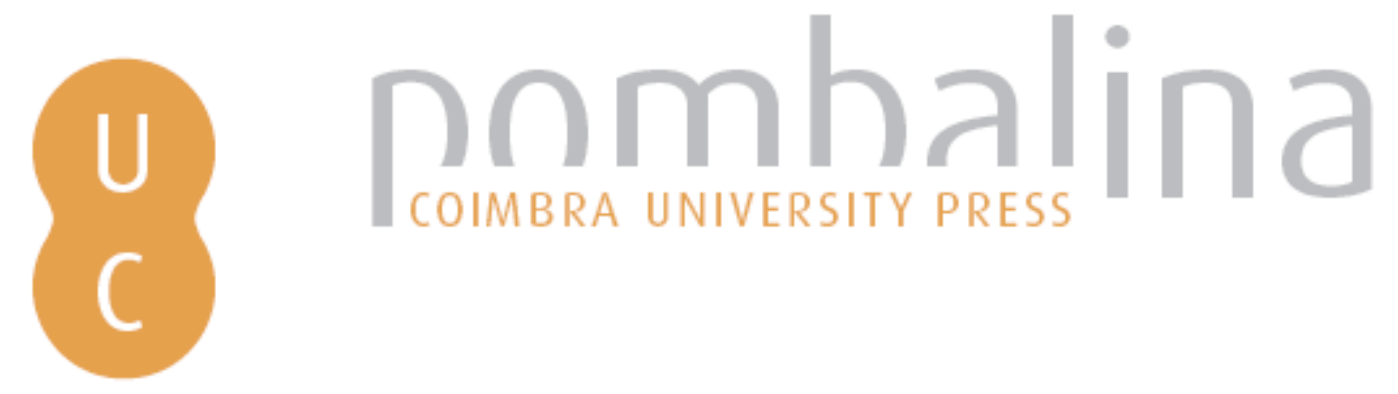

\title{
Reflexões sobre educação a distância a partir de Marx: considerações sobre tecnologias e trabalho docente
}

\author{
Autor(es): $\quad$ Mill, Daniel; Corrêa, André Garcia; Chaquime, Luciane Penteado \\ Publicado por: Imprensa da Universidade de Coimbra \\ URL \\ persistente: URI:http://hdl.handle.net/10316.2/47381 \\ DOI: $\quad$ DOI:https://doi.org/10.14195/978-989-26-1716-9_5 \\ Accessed : $\quad$ 26-Apr-2023 11:00:31
}

A navegação consulta e descarregamento dos títulos inseridos nas Bibliotecas Digitais UC Digitalis, UC Pombalina e UC Impactum, pressupõem a aceitação plena e sem reservas dos Termos e Condições de Uso destas Bibliotecas Digitais, disponíveis em https://digitalis.uc.pt/pt-pt/termos.

Conforme exposto nos referidos Termos e Condições de Uso, o descarregamento de títulos de acesso restrito requer uma licença válida de autorização devendo o utilizador aceder ao(s) documento(s) a partir de um endereço de IP da instituição detentora da supramencionada licença.

Ao utilizador é apenas permitido o descarregamento para uso pessoal, pelo que o emprego do(s) título(s) descarregado(s) para outro fim, designadamente comercial, carece de autorização do respetivo autor ou editor da obra.

Na medida em que todas as obras da UC Digitalis se encontram protegidas pelo Código do Direito de Autor e Direitos Conexos e demais legislação aplicável, toda a cópia, parcial ou total, deste documento, nos casos em que é legalmente admitida, deverá conter ou fazer-se acompanhar por este aviso.

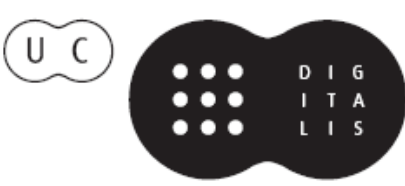



DANIEL MILL

Universidade Federal de São Carlos

mill@ufscar.br

ANDRÉ GARCIA CORRÊA

Universidade Federal de São Carlos

andregcorrea@gmail.com

LUCIANE PENTEADO CHAQUIME

Universidade Federal de São Carlos

luciane.penteado@gmail.com

REFLEX Õ ES SOBRE EDUCAÇÃOA DISTÂNCIA

A PARTIR DE MARX: CONSIDERAÇÕES SOBRE TECNOLOGIAS E TRABALHO DOCENTE

\section{Introdução}

A Educação a Distância (EaD) tem peculiaridades e especificidades que não estão presentes na Educação Presencial. Isto se deve, basicamente, ao fato de professor e aluno não compartilharem o mesmo espaço e tempo. Como implicação dessa característica fundamental da modalidade a distância, temos o uso intensivo das Tecnologias Digitais de Informação e Comunicação (TDIC). Todo o processo de ensino-aprendizagem na EaD que utiliza os meios digitais tem de ser mediado por uma TDIC, justamente por conta das barreiras espaço-temporais impostas à modalidade.

O uso intensivo de tecnologias agrega novos profissionais ao trabalho docente em EaD, bem como fragmenta o trabalho do professor num fenômeno denominado por Mill (2014) de polidocência. Se o trabalho docente está fragmentado e mediado intensamente por TDIC, poderíamos enxergar a polidocência sob as mesmas lentes que Marx e outros autores marxistas no 
que se refere à divisão, fragmentação e parcelamento do trabalho? Afinal de contas, a polidocência existe para lidar com as especificidades da EaD ou esta fragmentação estaria vinculada a outros interesses?

Antes de responder categoricamente tais perguntas, o texto propõe uma reflexão crítica sobre o trabalho docente em EaD, sem condenar ou rechaçar a modalidade a distância. Procuramos, aqui, encarar a polidocência como um fenômeno, entender suas origens e ponderar as possíveis implicações do parcelamento do trabalho docente na EaD mediado pelo uso de TDIC. As reflexões ora apresentadas, conforme mencionado acima, sustentam-se num referencial marxiano e marxista de compreensão das relações de trabalho. Além disso, são decorrentes de discussões teóricas realizadas no âmbito do Grupo de Estudos e Pesquisas sobre Inovação em Educação, Tecnologias e Linguagens (Grupo Horizonte) da Universidade Federal de São Carlos (UFSCar), como forma de analisar e entender as relações sociais que perpassam o trabalho docente mediado por tecnologias.

Partindo dos pressupostos acima delineados, as próximas seções deste artigo foram organizadas da seguinte maneira: na seção dois, apresentaremos a definição de polidocência, entendendo-a como a forma como se organiza o trabalho docente na modalidade EaD; a terceira seção traz algumas análises possíveis sobre a EaD, as TDIC e a polidocência a partir da perspectiva de Marx. Para tanto, enfocamos algumas categorias marxistas de análise como divisão do trabalho, maquinaria e cooperação, além de tratarmos das implicações da revolução científico-tecnológica para a polidocência, tendo como pano de fundo as contribuições de Braverman (2012). Por fim, traçaremos algumas considerações sobre as discussões realizadas ao longo do artigo.

\section{Polidocência: organização do trabalho docente na Educação a Distância}

Nesta etapa do texto, definiremos o termo polidocência. Em seguida, faremos um paralelo sobre o que Marx e outros autores têm a dizer sobre divisão do trabalho e o desenvolvimento científico tecnológico. Nosso 
intuito é mostrar paralelos entre o conceito de polidocência e o que já vinha sendo dito sobre o efeito de tecnologias na divisão do trabalho e nas relações sociais.

Mill (2014) define como polidocência o conjunto de profissionais responsáveis pelo processo de ensino-aprendizagem em EaD. Partindo dessa perspectiva, compreende-se que o trabalho docente na $\mathrm{EaD}$, diferentemente do que ocorre na educação presencial, em que um professor domina praticamente todo o processo $^{1}$, é fragmentado e cada etapa do trabalho do professor passa a ser fracionada e atribuída a um profissional diferente, que pode ou não ter formação para a docência. Isso acontece justamente pela necessidade que a modalidade impõe de, imprescindivelmente, ter uma TDIC mediando todo o processo de ensino-aprendizagem, seja na relação professor/aluno, seja no relacionamento do aluno com o material didático ao construir seu conhecimento.

No Quadro 1 encontramos uma descrição dos profissionais membros deste corpo responsável pelo ensino e a aprendizagem na EaD, conforme Mill (2014). Algumas nomenclaturas variam de uma instituição para outra. Também alguns profissionais podem acumular uma ou mais funções dependendo da instituição ou do modelo empregado. Por exemplo, para cortar custos é comum que o professor responsável pelo conteúdo não seja o mesmo profissional que acompanha os alunos durante a oferta. Paga-se a um profissional que elabora o conteúdo que será replicado inúmeras vezes em quantas ofertas forem possíveis. Uma disciplina também pode não ter tutores virtuais por ser ofertada para poucos alunos.

1 Um mesmo professor, na educação presencial, é responsável por todas as etapas que envolvem o processo de ensino-aprendizagem, ou seja, ele planeja a aula, escolhe o conteúdo que será abordado, as mídias, instrumentos e materiais didáticos que utilizará na aula, acompanha os alunos em suas atividades e, ainda, avalia o processo. 
QUADRO 1. Membros da polidocência e de apoio aos cursos EaD

\begin{tabular}{|c|c|}
\hline $\begin{array}{c}\text { Profissionais } \\
\text { envolvidos na } \\
\text { polidocência }\end{array}$ & Descrição da função na oferta de cursos EaD \\
\hline $\begin{array}{l}\text { Professor- } \\
\text { conteudista }\end{array}$ & $\begin{array}{l}\text { É, necessariamente, um especialista da área da disciplina. Cuida da } \\
\text { elaboração dos conteúdos e materiais didáticos em diferentes mídias e } \\
\text { encarrega-se de adequar metodologicamente os conceitos e atividades } \\
\text { de aprendizagem ao perfil do egresso do curso. }\end{array}$ \\
\hline $\begin{array}{l}\text { Professor- } \\
\text { formador }\end{array}$ & $\begin{array}{l}\text { Também chamado de professor-aplicador, seu papel consiste no acom- } \\
\text { panhamento dos alunos durante a oferta da disciplina. Também é res- } \\
\text { ponsável por gerenciar os tutores e realizar webconferências. Nem } \\
\text { sempre está presente no AVA e, muitas vezes, os tutores virtuais ficam } \\
\text { como únicos responsáveis no acompanhamento dos alunos. Sua pre- } \\
\text { sença aumenta os custos para a instituição ofertante do curso e reduz } \\
\text { a autonomia dos tutores. }\end{array}$ \\
\hline Tutores virtuais & $\begin{array}{l}\text { Normalmente são especialistas da área da disciplina ou do curso. De- } \\
\text { vem acompanhar o aluno em seus estudos orientando-o em suas di- } \\
\text { ficuldades. São necessários quando a quantidade de alunos é muito } \\
\text { grande para que apenas o professor formador fique responsável pela } \\
\text { turma. A razão alunos/tutor varia de uma instituição para outra e tam- } \\
\text { bém impacta nos custos, mas a função do tutor virtual é muito com- } \\
\text { plexa e trabalhosa para atender um grupo muito grande de alunos. }\end{array}$ \\
\hline $\begin{array}{c}\text { Tutores } \\
\text { presenciais }\end{array}$ & $\begin{array}{l}\text { São sujeitos importantes que podem ficar de fora do processo em } \\
\text { determinados modelos de EaD para redução de custos. Geralmente, } \\
\text { possuem conhecimento generalista sobre o tema em comparação com } \\
\text { o tutor virtual. Fazem atendimento local aos alunos. auxiliando em } \\
\text { atividades pontuais. }\end{array}$ \\
\hline $\begin{array}{c}\text { Equipe } \\
\text { multidisciplinar }\end{array}$ & $\begin{array}{l}\text { Composta por especialistas de mídia, impressa, audiovisual, virtual, vi- } \\
\text { deoconferência e/ou webconferência. Muitos educadores de EaD con- } \\
\text { sideram a equipe multidisciplinar como apoio técnico e não docente. } \\
\text { No entanto, Mill (2014) considera que são peças chave da equipe po- } \\
\text { lidocente por atuarem no desenvolvimento qualitativo do trabalho do- } \\
\text { cente. Por fim, o autor argumenta que sem a equipe multidisciplinar, o } \\
\text { docente não conseguiria oferecer sua "aula". }\end{array}$ \\
\hline $\begin{array}{l}\text { Designer Ins- } \\
\text { trucional (DI) }\end{array}$ & $\begin{array}{l}\text { Possui formação pedagógica mais direcionada para atividades de en- } \\
\text { sino-aprendizagem da modalidade EaD. É responsável pela adequação } \\
\text { do conteúdo do curso ou disciplina às várias mídias adotadas pela } \\
\text { instituição mantenedora. O designer instrucional ou projetista traba- } \\
\text { lha em parceira com diversos profissionais da polidocência, como o } \\
\text { professor-conteudista e o professor- formador. Segundo o autor, essa } \\
\text { relação próxima com outros profissionais ocasionalmente gera tensão } \\
\text { quando o DI toma para si a responsabilidade pela disciplina. }\end{array}$ \\
\hline
\end{tabular}




\begin{tabular}{|c|l|}
\hline $\begin{array}{c}\text { Profissionais } \\
\text { envolvidos na } \\
\text { polidocência }\end{array}$ & \multicolumn{1}{|c|}{ Descrição da função na oferta de cursos EaD } \\
\hline $\begin{array}{c}\text { Equipe coorde- } \\
\text { nadora }\end{array}$ & $\begin{array}{l}\text { A equipe coordenadora tem importância no processo de ensino- } \\
\text {-aprendizagem em EaD, pois suas decisões impactam diretamente no } \\
\text { trabalho docente na medida em que decidem o modelo de EaD a ser } \\
\text { implementado, o que implica na autonomia e liberdade dos demais } \\
\text { profissionais. }\end{array}$ \\
\hline $\begin{array}{c}\text { Equipe de } \\
\text { apoio técnico }\end{array}$ & $\begin{array}{l}\text { Não tem atuação direta com a docência virtual. São profissionais que } \\
\text { exercem suas atividades no polo de apoio ou na sede da instituição } \\
\text { ofertante do curso. Realizam atividades como apoio logístico, hel- } \\
\text { pdesk, apoio técnico e administrativo no polo etc. }\end{array}$ \\
\hline
\end{tabular}

Fonte: Compilação própria a partir de Mill (2014).

\section{Reflexões sobre Educação a Distância, tecnologias digitais de informação e comunicação e polidocência a partir de Marx}

Buscaremos, nessa seção, utilizar as categorias marxianas "maquinaria", "divisão do trabalho", "manufatura" e "cooperação", presentes em O Capital, bem como reflexões de autores marxistas, para pensarmos a modalidade a distância na atualidade e suas implicações para o trabalho docente.

\subsection{Maquinaria e suas semelhanças com as TDIC}

Pensarmos a polidocência tendo em contraposição categorias de Marx presentes em O Capital faz-se necessário se quisermos compreender qual é, de fato, o impacto dessa dinâmica do processo de ensino-aprendizagem caracterizado pela divisão do trabalho docente. Dada a relação intrínseca entre EaD, nos moldes da educação virtual, e as TDIC, quais paralelos poderíamos obter entre o que Marx nos diz sobre a maquinaria e o trabalho e a mediação do processo de ensino-aprendizagem na EaD por TDIC? O que a obra O Capital aborda sobre maquinaria é aplicável à polidocência?

Em primeiro lugar, é preciso afirmar que, mesmo que seja imprescindível o uso de TDIC para se fazer EaD e que a tecnologia necessariamente tenha 
de mediar o processo de ensino-aprendizagem na modalidade a distância, não se faz EaD sem o docente. Em outras palavras, as TDIC não são capazes de gerar valor. Para Marx (1990), a maquinaria é capaz apenas de transferir valor para o produto final. Se as TDIC são a maquinaria em EaD, o trabalho docente ainda é imprescindível para a realização do processo de ensino-aprendizagem. As TDIC podem aumentar o alcance do trabalho docente, seja na quantidade numérica de alunos, seja no alcance geográfico, mas o processo de ensino-aprendizagem ainda é fruto do trabalho docente.

Quando Marx (1990) fala sobre a maquinaria, uma das consequências de seu desenvolvimento é que o uso da força física no trabalho já não é mais imprescindível. No início, o preço pago ao trabalhador por sua força de trabalho precisava prover por toda sua família. Com o desenvolvimento da maquinaria, todos os integrantes da família ingressam na indústria, repartindo a força de trabalho do homem entre todos os indivíduos do núcleo familiar. O que, consequentemente, causa uma desvalorização do preço pago ao trabalhador.

A polidocência fragmenta também a força de trabalho do docente. Nela, o processo de ensino-aprendizagem encontra-se espalhado entre diversos profissionais. As etapas de planejamento, gestão e oferta também estão divididas em etapas e profissionais diferentes. Essa fragmentação pode provocar uma desvalorização do trabalho do professor, se a instituição responsável pela EaD sendo ofertada tiver como propósito único a maximização dos lucros e não a qualidade de ensino.

Outra consequência do uso das TDIC em EaD é o prolongamento do dia de trabalho. Ao falar sobre a maquinaria, Marx (1990) coloca que os avanços tecnológicos proporcionados pelo seu desenvolvimento são paradoxais, pois ao ampliarem a capacidade de produção, exigindo menos tempo para produzir mais, acabam fazendo com o que o dia de trabalho se prolongue muitas vezes. No caso da $\mathrm{EaD}$, aluno e professor encontram-se separados no espaço e no tempo, ou seja, não existe mais o período da aula que encontramos na educação presencial. O trabalho do professor presencial já tem uma carga horária grande fora da sala de aula, planejamento e correções de avaliações fazem parte do seu cotidiano e boa parte do seu trabalho é feita fora da sala de aula ou mesmo fora do espaço físico 
da escola. Na EaD isso se intensifica, especialmente para o professor-coordenador $^{2}$ e para o tutor virtual (Mill, 2012).

O professor-coordenador trabalha na etapa de planejamento e de oferta. $\mathrm{Na}$ etapa de planejamento ele lida com prazos para entrega do material a ser utilizado. Durante a oferta, ele coordena a equipe de tutores e interage com o aluno. Em nenhuma dessas duas etapas existe um horário fixo de trabalho. Ele precisa dar conta de atender os prazos e precisa estar disponível para os alunos e tutores.

O tutor virtual tem um contato muito mais intenso com o aluno. As respostas às dúvidas dos alunos devem ser dadas com celeridade para que eles consigam proceder sem entraves na construção do seu conhecimento. Isso faz com que o tutor virtual deva ficar de prontidão. Como muitos alunos já estão no mercado de trabalho, o período noturno e os finais de semana acabam sendo os mais utilizados para acesso do AVA e realização das atividades. Existem instituições que colocam um prazo de nenhuma dúvida sem resposta por mais de 24 horas, o que faz com que o tutor fique à disposição do aluno praticamente nos sete dias da semana. Sem um horário fixo de trabalho, ele também está de prontidão a qualquer momento do dia.

A partir do exposto, é possível dizer que as TIDC podem também causar um paradoxo assim como na maquinaria descrita por Marx, uma vez que surgem com a promessa de flexibilizar o trabalho, mas podem fazer com que o tutor e o professor estejam o tempo todo trabalhando. Essa perspectiva de análise assemelha-se à conclusão de Frigotto (2005), no sentido em que o autor, ao abordar as mudanças mais recentes no mundo do trabalho, enfatiza que a ciência e a tecnologia, as quais, em sentido ontológico, deveriam liberar tempo de trabalho criativo aos seres humanos, sob a égide do capitalismo, acabam, por um lado, intensificando o trabalho e, por outro, gerando precarização.

2 Em algumas situações, o professor-conteudista acumula a função de professor-formador, fazendo com que sua atuação no curso seja expandida e passe a abranger, além da etapa do planejamento, a fase de oferta. Nesses casos, utiliza-se a denominação de professor-coordenador. 


\subsection{Divisão do trabalho e Manufatura: paralelos com a polidocência}

No tópico anterior, traçamos um paralelo entre os argumentos de Marx a respeito da maquinaria e as TDIC. Poderíamos fazer o mesmo sobre a divisão do trabalho e a manufatura tendo como pano de fundo a polidocência? A divisão do trabalho na polidocência é clara, mas é uma fragmentação do trabalho docente e não da manufatura. Portanto, seriam mais uma vez intercambiáveis os argumentos de Marx a uma visão crítica da polidocência?

Em O Capital, Marx (1990) diz que a manufatura tem duas origens: pode ser a combinação de diversos ofícios autônomos que são desautonomizados e unilaterizados até que se tornem apenas parcelas complementares do mesmo processo. Também pode ser a fragmentação de um mesmo ofício individual em diversas operações particulares, isoladas de forma que cada uma dessas etapas se torna função exclusiva de cada operário em particular.

Ao examinarmos os integrantes que constituem a polidocência, podemos encontrar aqueles de ofícios diversos à docência que foram integrados ao processo de ensino-aprendizagem para a modalidade EaD. Também é possível caracterizar profissionais que ficaram com parcelas do trabalho docente que na Educação Presencial é realizado por apenas um profissional. Em outras palavras, não só o trabalho docente se encontra fragmentado na EaD, mas temos a introdução de outros profissionais que não fazem parte do ensino-aprendizagem em outras situações que não a da modalidade a distância. O Quadro 2, abaixo, demonstra esta divisão.

QUADRO 2. Divisão do trabalho na polidocência

\begin{tabular}{|c|c|}
\hline $\begin{array}{c}\text { Ofícios diversos à docência integrados ao } \\
\text { processo de ensino-aprendizagem na EaD }\end{array}$ & Fragmentação do trabalho docente \\
\hline & Professor-Conteudista \\
Equipe Multidisciplinar & Professor-Formador \\
Equipe Coordenadora & Tutor Virtual \\
Equipe de apoio Técnico & Tutor Presencial \\
& Designer Instrucional \\
\hline
\end{tabular}

Fonte: Organização própria. 
Entre os profissionais da polidocência, o professor-conteudista, o professor-formador, o tutor virtual, o tutor presencial e o designer instrucional estão todos encarregados de atividades diretamente ligadas ao ensino-aprendizagem. Em outras palavras, assumem parcelas do que seria o trabalho docente na Educação Presencial. De forma parcelada, planejam a disciplina, elaboram atividades e avaliações, interagem com os alunos e os orientam na sua construção de conhecimento, bem como tiram dúvidas e sanam problemas.

A Equipe Multidisciplinar, a Equipe Coordenadora e a de ApoioTécnico exercem atividades diversas à docência, mas foram acrescentadas ao processo devido às especificidades da EaD. A Equipe Multidisciplinar e a Equipe de Apoio Técnico surgem para suprir necessidades específicas das TDIC. O uso de diversas mídias vai exigir profissionais para lidar com audiovisual, webconferência, mídia impressa etc. A Equipe de Apoio Técnico tem de lidar com problemas relativos às tecnologias que veiculam as mídias desenvolvidas pela Equipe Multidisciplinar.

A Equipe Coordenadora surge como um corpo que gerencia todo esse processo. Como Mill (2014) nos explica, ela influencia diretamente aspectos muito importantes da atividade docente como autonomia e liberdade dos profissionais da polidocência. Braverman (2012), fala da gerência como um instrumento do capitalista para controlar. A gerência, para o capital, acarreta uma relação antagônica entre os que executam o trabalho e os que o administram.

Aqui retornamos à questão sob qual viés o modelo de EaD está sendo empregado. Se pensarmos em um modelo em que a qualidade do ensino seja a prioridade para a instituição, a Equipe Coordenadora irá trabalhar administrando os demais profissionais no sentido de melhorar o processo de ensino-aprendizagem mediado pelas TDIC. Se o modelo for implementado sob um viés puramente capitalista, visando a maximização do lucro e a minimização dos custos, a Equipe Coordenadora terá uma relação com os demais profissionais semelhante à descrita por Braverman (2012), marcada pelo antagonismo daqueles que trazem a sua força de trabalho e os que empreendem em extrair dessa força de trabalho a vantagem máxima para o capitalista.

Sobre a fragmentação do trabalho, Braverman (2012) ainda afirma que sua divisão parcelada depende da escala de produção. Sem quantidades suficientes ela é impraticável. Cada passo representa uma poupança no tempo de 
trabalho, mas essa poupança só pode ser efetiva em larga escala. A maneira de se poupar mais tempo na produção encontra-se na separação das operações em diferentes trabalhadores. Uma das vantagens da EaD é dar alcance a um número muito maior de pessoas que na Educação Presencial. Enquanto uma sala de aula pode conter um certo número de alunos sob a responsabilidade do professor, um curso a distância pode ter um número muito maior de alunos. Esse número pode variar de acordo com a relação tutor/aluno, mas sempre será maior que na Educação Presencial. Se ofertada a um número pequeno de alunos, o número de profissionais da polidocência forçosamente será reduzido.

Desta forma, pode-se inferir que a polidocência acontece na modalidade a distância por dois motivos: a) o uso de TDIC gera necessidades específicas à EaD que não encontramos na Educação Presencial que serão atendidas por profissionais como a Equipe Multidisciplinar e a Equipe de Apoio Técnico e; b) o número elevado de alunos força uma subdivisão do trabalho docente em diversos profissionais como o tutor virtual e o designer instrucional, pois a carga de trabalho seria demasiada para apenas um único docente.

Portanto, a divisão do trabalho na polidocência pode ser vista pelo viés capitalista: se aumentarmos a relação tutor/aluno, contratarmos um professor-conteudista e que não seja também o professor-coordenador, os custos serão reduzidos, por exemplo. No entanto, pela própria natureza da $\mathrm{EaD}$, acreditamos que não seja possível executá-la sem fragmentar o trabalho docente por especificidades da própria modalidade, mesmo que não seja a maximização dos lucros o principal objetivo. Desta forma, a fragmentação do trabalho docente, o acréscimo de outros profissionais alheios ao processo de ensino-aprendizagem relacionado ao manejo das TDIC e uma Equipe Coordenadora que gerencia este processo e todos os envolvidos se faz necessária para que o aluno em EaD tenha condições de conduzir sua construção de conhecimento.

\subsection{Cooperação e polidocência na EaD}

Ao abordar a cooperação como uma forma de trabalho em que os trabalhadores atuam conjuntamente, no mesmo processo produtivo ou em processos 
diferentes, mas interligados, de acordo com um planejamento comum, Marx (1990) enfatiza alguns aspectos, os quais, em nossa compreensão, podem ser utilizados para se pensar criticamente a docência na EaD.

O primeiro deles diz respeito à geração de uma força produtiva nova a partir da organização cooperativa do trabalho, à qual Marx (1990) denomina força coletiva ou trabalhador coletivo. Segundo esclarece, sendo o ser humano um ser social, a junção de diversos trabalhadores num único processo torna-se motivante para cada um deles, gerando uma força de trabalho que alcança muito além da potencialização do trabalho individual. Quando trazemos essa ideia para a modalidade a distância, especialmente para os profissionais nela atuantes, podemos pensar a polidocência como uma forma cooperativa de trabalho. Isso porque, conforme dito anteriormente, para que um curso EaD seja implementado, é necessário o envolvimento de diferentes trabalhadores que, atuando como uma força coletiva no processo, executam, cada um, uma parte da tarefa que, na educação presencial, um único professor exerce isoladamente. Dessa maneira, a polidocência se configuraria como o trabalhador coletivo de Marx (1990), na medida em que une potenciais individuais de diferentes profissionais num único processo de ensino-aprendizagem.

O segundo aspecto apontado por Marx (1990) ao tratar da cooperação articula-se ao primeiro na medida em que o autor afirma ser a cooperação uma forma de organizar o trabalho especialmente utilizada em processos produtivos em que a tarefa a ser executada é complexa. Nessas situações, conforme esclarece, a simples distribuição das diferentes operações entre os trabalhadores faz com que elas sejam realizadas simultaneamente, comprimindo o tempo de trabalho necessário à execução de todas as tarefas e tornando o resultado mais eficiente do ponto de vista do capitalista. Essas considerações nos remetem imediatamente à complexidade que caracteriza o trabalho docente que, quando pensado sob as exigências da $\mathrm{EaD}$, se amplifica. Nesse sentido, considerando as especificidades da educação virtual, a oferta de cursos tendo apenas um profissional acarretaria morosidade ao processo de ensino-aprendizagem a ponto de inviabilizá-lo em alguns casos, pois uma única pessoa teria que planejar as disciplinas, montá-las no AVA, elaborar atividades e acompanhar os alunos, além de avaliá-los, entre outras tarefas inerentes ao trabalho docente. Desse modo, a fragmentação das tarefas e o 
trabalho cooperativo dos diferentes profissionais diminui o tempo gasto no processo e lhe confere maior eficiência, tanto do ponto de vista do planejamento quanto da oferta dos cursos.

Um terceiro aspecto salientado por Marx (1990) ao analisar a cooperação diz respeito à aglomeração dos trabalhadores num mesmo local. Para o autor, essa é uma condição para que a cooperação aconteça, uma vez que os trabalhadores utilizarão, juntos e simultaneamente, os meios de produção disponíveis. Associado a isso, Marx (1990) deixa claro que a cooperação só se dá quando um mesmo capitalista compra a força de trabalho coletiva, pois o trabalho coletivo, segundo ele, necessita de um direcionamento da mesma maneira que uma orquestra exige um maestro para que um concerto seja produzido. Essa função de direção é desempenhada pelo capital personificado no capitalista.

Acerca desse terceiro aspecto, vale ressaltar que Marx (1990) fez reflexões a partir de um contexto histórico específico, do qual as TDIC não faziam parte. Nos tempos atuais, caracterizados por uma base científica e técnica do processo produtivo à qual Frigotto (2005) denomina "digital-molecular", o teletrabalho, isto é, o trabalho realizado longe do ambiente da empresa ou da fábrica já é realidade. Além disso, é muito utilizado pelo capital como estratégia para aumentar a opressão sobre o trabalhador, uma vez que, ao trabalhar de sua casa fica a seu critério organizar o tempo de trabalho ${ }^{3}$. Assim, o que comumente ocorre é que, sob a ilusão de que de casa terá maior liberdade e estará próximo da família, o trabalhador acaba ampliando sua jornada diária porque aumenta o tempo gasto em atender às demandas do seu emprego em detrimento de seu tempo de lazer e, com isso, perde direitos trabalhistas como o descanso semanal remunerado, entre outros. Essa situação é bastante característica, em especial entre os tutores virtuais, a começar pelo fato de não terem sua profissão regulamentada. Esses membros da polidocência geralmente desempenham seu papel nos cursos EaD trabalhando de suas casas, tendo que utilizar computadores, internet e ener-

3 Também, a infraestrutura necessária para exercer o trabalho fica a cargo do próprio profissional que deve adquirir um computador e arcar com custos de energia elétrica e acesso a internet de banda larga com uma conexão rápida o suficiente para mídias pesadas. 
gia elétrica custeados por eles próprios, além de não disponibilizarem de mobiliário adequado do ponto de vista ergonômico e muito menos de uma jornada diária de trabalho claramente definida por um contrato e outros direitos trabalhistas dos quais são alijados. A partir dessas considerações e no caso da EaD, foco do nosso trabalho, podemos dizer que esse terceiro aspecto sobre a cooperação, apontado por Marx (1990), foi reconfigurado no atual estágio de desenvolvimento do capitalismo de forma que já é possível ao capitalista gerenciar o trabalho coletivo sem que os trabalhadores estejam reunidos num mesmo espaço.

Por fim, um quarto aspecto levantado por Marx (1990) ao explanar sobre a cooperação refere-se ao fato dela ser adotada quando se deseja uma produção em larga escala.Ao se pensar em educação na modalidade a distância, o paralelo que se pode fazer é bastante claro. Isso porque a EaD tem se expandido consideravelmente nos últimos dez anos em decorrência de políticas que fomentam a modalidade como forma de democratizar o acesso à educação. Nesse contexto, o que se busca, prioritariamente em instituições privadas, é alcançar mais pessoas sem que para isso seja preciso aumentar muito os investimentos. Desse modo, os cursos EaD são pensados em larga escala, uma vez que uma única instituição ofertante pode ter diversos polos espalhados por uma região ou mesmo pelo país todo, aumentando consideravelmente a quantidade de alunos em comparação ao que teria se o curso fosse ofertado presencialmente, tendo as dimensões físicas da sala de aula como limitadores do número de alunos. Ao lado disso, o trabalho docente na EaD organizado em polidocência permite uma redução nos custos de oferta de cursos, pois geralmente o curso é planejado e os materiais são preparados uma única vez e podem ser replicados inúmeras vezes, exigindo apenas poucos ajustes em cada oferta posterior.

Em vista dos aspectos levantados acerca da cooperação em Marx (1990), arriscamos dizer que a polidocência na $\mathrm{EaD}$ pode ser compreendida como o trabalhador coletivo que, ao mesmo tempo em que potencializa a força de trabalho individual de cada profissional envolvido na implementação de cursos na modalidade a distância, pode gerar condições que precarizam o trabalho docente como forma de aumentar a eficiência na oferta de cursos. Corroborando a precarização, Braverman (2012) aponta uma crescente insa- 
tisfação em relação às condições de trabalho, a qual seria paradoxalmente decorrente da revolução científico-tecnológica. Para o autor, a subdivisão do trabalho em operações mínimas, incapazes de suscitar interesse ou empenhar a capacidade de pessoas de acordo com seus níveis de instrução, gera grande insatisfação entre os trabalhadores. O autor argumenta que alterações no processo produtivo não têm o objetivo de reduzir a insatisfação com o trabalho. Quando alterações no processo são feitas, a intenção é redução de custos e maximização dos lucros.

Mill (2014) também discorre sobre possíveis aspectos negativos provocados pela polidocência no mesmo sentido em que Braverman nos fala sobre consequências da divisão do trabalho.

Verifica-se, pois, que a organização do trabalho de forma coletiva, cooperativa, evidencia as tensões possíveis entre gestores e trabalhadores e, ainda, distancia a forma de trabalho dos interesses dos trabalhadores. Nesse sentido, a fragmentação do trabalho na EaD passa a ser estimulada em experiências de EaD com vistas à redução de custos ou otimização dos ganhos financeiros. Numa perspectiva crítica, essa discussão traz consigo questões de base como divisão técnica e social do trabalho, autonomia e controle do trabalho, processo cooperativo, trabalho em equipe, trabalho coletivo, equipes de caráter aditivo, equipes integradas, entre outros (Mill, 2014, p.30).

Pelo que discutimos ao longo do texto, não podemos afirmar categoricamente que a divisão do trabalho docente na EaD nos moldes da polidocência necessariamente implica em aspectos negativos e precarização do trabalho. Organizar o processo e a divisão do trabalho com o único objetivo de cortar custos ou maximizar lucros causarão tais aspectos negativos. Também não é possível creditar às TDIC tais males. Como dito anteriormente, não há como ter o processo de ensino-aprendizagem em EaD sem a mediação das TDIC, pois é por meio delas que são veiculadas as mídias com o conteúdo de cursos e disciplinas, além de intermediar toda a interação entre alunos, professores e tutores. Em outras palavras, a função das TDIC não é eliminar custos ou maximizar lucros, mas sim intermediar todo o processo. No entanto, elas podem ser (e muitas vezes são) usadas com estas finalidades. 


\section{Considerações Finais}

Ao iniciarmos este texto, colocamos questões norteadoras para refletirmos criticamente sobre a Educação a Distância, as tecnologias e o trabalho docente nela envolvido. As questões foram: se o trabalho docente se encontra fragmentado e mediado intensamente por TDIC, poderíamos enxergar a polidocência sob as mesmas lentes que Marx e outros autores marxistas no que se refere à divisão, fragmentação e parcelamento do trabalho? Afinal de contas, a polidocência existe para lidar com as especificidades da EaD ou esta fragmentação estaria vinculada a outros interesses?

Sem nenhuma pretensão de esgotá-las, as análises realizadas, especialmente na seção três em que nos baseamos em categorias marxistas para pensar a polidocência e as tecnologias presentes na educação virtual, trouxeram elementos reveladores sobre como o trabalho docente na modalidade, quando é organizado com vistas a maximizar lucros e aumentar produtividade, gera, entre outras consequências, perdas trabalhistas para os profissionais, tornando-os insatisfeitos e precarizando suas condições de trabalho.

A reflexão realizada permitiu, ainda, trazer à tona a importância de que pesquisas sobre o trabalho docente e o uso de tecnologias na EaD sejam realizadas de uma perspectiva crítica, com vistas a desvelar aspectos opressores da expansão da modalidade, os quais, visando atender os interesses de grupos econômicos dominantes na área, ficam encobertos sob a bandeira da democratização do acesso à Educação. De fato, acreditamos que não há como fazer EaD sem a polidocência mediada pelo uso das TDIC, pelo menos não nos moldes da educação virtual. Compreendemos que a gestão das TDIC e da polidocência podem ser usadas para outros fins que não a qualidade do processo de ensino-aprendizagem, mas sim como meios de atender aos interesses do capital. Mas isto não significa que a EaD é uma modalidade fadada a um modelo distópico que explora seus profissionais e massifica o acesso à Educação. 


\section{Referências bibliográficas}

BRAVERMAN, H. (2012). Trabalho e capital monopolista: a degradação do trabalho no Século XX. Rio de Janeiro: LTC.

FRIGOTTO, G. (2005). Concepções e mudanças no mundo do trabalho e o ensino médio. In G. FrigotTo, M. CiavatTA, M. \& M. RAmOs (Org.). Ensino médio integrado: concepção e contradições (pp. 57-82). São Paulo: Cortez.

MARX, K. (1990). O Capital. Lisboa: Avante.

MILL, D. (2012). Docência Virtual: uma visão crítica. São Carlos: EdUFSCar.

MILL, D. (2014). Sobre o conceito de polidocência ou sobre a natureza do processo de trabalho pedagógico na Educação a Distância. In: D. MILL, L. R. C. RIBEIRO \& M. G. R. OliveIrA (Org.). Polidocência na educação a distância: múltiplos enfoques. São Carlos: EdUFSCar. 